\title{
Integrated waste management as a climate change stabilisation wedge for the Maltese islands
}

Waste Management \& Research 31(1) 73-79

(C) The Author(s) 2013

Reprints and permission:

sagepub.co.uk/journalsPermissions.nav DOI: $10.1177 / 0734242 \times 12468198$

wmr.sagepub.com

(S)AGE

\author{
Clyde Falzon ${ }^{1}$, Simon G Fabri² and Steven Frysinger ${ }^{3}$
}

\begin{abstract}
The continuous increase in anthropogenic greenhouse gas emissions occurring since the Industrial Revolution is offering significant ecological challenges to Earth. These emissions are leading to climate changes which bring about extensive damage to communities, ecosystems and resources. The analysis in this article is focussed on the waste sector within the Maltese islands, which is the largest greenhouse gas emitter in the archipelago following the energy and transportation sectors. This work shows how integrated waste management, based on a life cycle assessment methodology, acts as an effective stabilisation wedge strategy for climate change. Ten different scenarios applicable to the Maltese municipal solid waste management sector are analysed. It is shown that the scenario that is most coherent with the stabilisation wedges strategy for the Maltese islands consists of $50 \%$ landfilling, $30 \%$ mechanical biological treatment and $20 \%$ recyclable waste export for recycling. It is calculated that $16.6 \mathrm{Mt}$ less $\mathrm{CO}_{2}$-e gases would be emitted over 50 years by means of this integrated waste management stabilisation wedge when compared to the business-as-usual scenario. These scientific results provide evidence in support of policy development in Malta that is implemented through legislation, economic instruments and other applicable tools.
\end{abstract}

\section{Keywords}

Stabilisation wedges strategy, integrated waste management, climate change, greenhouse gas, waste management in Malta, recycling, life cycle assessment

\section{Introduction}

Waste is the most significant contributor to greenhouse gas (GHG) emissions in the Maltese islands following the sectors of energy generation and transportation. According to the national GHG inventory, transport and energy (combined) contribute $87.9 \%$ of the total GHG emissions for Malta, and waste contributes $6.6 \%$ (MRRA, 2009a). The remaining portion of emissions comes from industrial processes, agriculture and solvents. The $6.6 \%$ contribution from waste translates to approximately $165 \mathrm{Gg}$ of $\mathrm{CO}_{2}$-e in absolute terms (MRA, 2011).

The main objective of this article is to assess the current waste management practices on the Maltese islands, concentrating especially on the influence of such practices on GHG generation, and to propose an integrated waste management strategy and a life cycle assessment (LCA) methodology aimed at stabilising and reducing GHG emissions from Malta.

The underlying framework governing the analysis described in this article is the concept of 'stabilisation wedges' introduced by Pacala and Socolow (Pacala and Socolow, 2004), which aims to find solutions to the problem of anthropogenic GHG emissions. According to the Carbon Mitigation Initiative, dramatic climate change can only be prevented if 200 billion tons of carbon emissions are avoided worldwide over the next 50 years (Hotinski, 2007). The stabilisation wedges concept proposes the combined use of several strategies, each of which reduces annual
GHG emissions over time, linearly increasing up to $1 \mathrm{Gt} /$ year of emission reductions in the fiftieth year since commencement. If the reduction in carbon emissions per year due to each individual strategy is plotted against time it leads to a wedge-like shape on the graph-hence the term stabilization wedges. Pacala and Socolow (2004) estimated that seven such actions (also called wedges) could have the potential to lead to stabilization (nonincrease) of carbon emissions in the time span of half a century. They also postulated that the targets set by the stabilisation wedges strategy could be achieved by current scientific, technical and industrial knowledge, suggesting actions such as energy efficiency and conservation, fossil fuel switching strategies and use of renewable energy sources to contribute to the wedges. However, they left open the possibility for other technologies or strategies to fit into their model (Hotinski, 2007).

1WasteServ Malta Ltd, Marsaskala, Malta

2Department of Systems \& Control Engineering, University of Malta, Msida, MSD, Malta

3James Madison University, Integrated Science and Technology

Program, Harrisonburg, VA, USA

\section{Corresponding author:}

Clyde Falzon, WasteServ Malta Ltd, EkoCentre, Triq il-Latmija, Marsaskala MSK 4613, Malta.

Email: clyde.falzonawasteservmalta.com 
The work documented in this article uses the Maltese islands as a case study. The Maltese islands, located in the middle of the Mediterranean Sea, form an archipelago of six islands, three of which are very small and uninhabited. The total land area is of around $316 \mathrm{~km}^{2}$. Malta is the largest island with an area of 246 $\mathrm{km}^{2}$ (Micallef and Sammut, 2010) that accommodates 92\% of the total population, which just exceeded 417,000 inhabitants in 2011 (Eurostat, 2011). The rest of the population live on the smaller islands of Gozo and Comino (NSO, 2010a). Officially known as the Republic of Malta, this politically independent country [which is also a full member of the European Union (EU)] is the third most densely populated state (Ginige, 2008) in the world. Although the nominal density, when considering only permanent residents, is just over 1300 persons per square kilometre (NSO 2010b), this statistic increases significantly owing to the large number of tourists who visit each year (1.2 million tourists in 2009) (NSO 2010b). The services industry is the highest gross domestic product (GDP) contributor to Malta's economy (Micallef and Sammut, 2010).

When compared with several other countries, the Maltese islands offer several challenges and 'unique working conditions' (WasteServ, 2011) for the management of waste. This is owing to a relatively high population density, leading to a large concentration of waste per unit area, and a small land area that is also separated physically from the rest of the European continent by the Mediterranean Sea, which leaves very little space for landfilling. The major developments in the waste sector occurred after 2002. The old un-engineered landfill was decommissioned and landfilling started to be practised in a new engineered landfill with gas recovery. The Sant Antnin Waste Treatment plant was upgraded with a mechanical biological treatment and anaerobic digestion plants. Furthermore, a new incinerator was commissioned to treat clinical waste, animal by-products and certain types of hazardous wastes.

In 2008 the rate of municipal solid waste (MSW) generation in Malta averaged at $696 \mathrm{~kg}$ per inhabitant, exceeding the EU average of $524 \mathrm{~kg}$ per inhabitant. Of this waste, an estimated 93\% was landfilled and the rest (7\%) was exported for recycling (Eurostat, 2010). The organic content of Maltese MSW is estimated to be around 53\% (JRC, 2007). Nearly all the organic fraction of MSW was landfilled prior to the commissioning of the anaerobic digestion (AD) plant, which took place at the end of 2010 (WasteServ, 2008).

The application of integrated waste management techniques as a novel stabilisation wedge was first proposed and evaluated by Bahor et al. (2009). This wedge consists of shifting the amounts of MSW from un-engineered landfilling to recycling and composting, waste-to-energy and advanced landfilling. It is called the waste wedge scenario (Bahor et al., 2009) and is also approved by the EU to combat climate change (EU, 2005).

\section{Materials and methods}

\section{LCA methodology}

This research study follows a LCA methodology in which the goal is to first quantify and then reduce GHG emissions generated by different waste management scenarios in the Maltese islands.

This work considered the components of the current Maltese waste management infrastructure together with the infrastructure planned to be built as mentioned in the Waste Management Plan for the Maltese Islands (MRRA, 2009b). The Maltese population, MSW and GHG generation trends, together with other local characteristics, were also considered to make this study reflect the real Maltese scenario.

The following boundaries and assumptions are used in this study:

Boundary 1-GHGs generated by the transport of waste are considered to be relatively insignificant. In fact, GHG generated by the transportation of waste amounts to less than $5 \%$ of the total GHG generated by MSW (Skovgaard et al., 2008)

Boundary 2-for the scope of this study only the environmental effects owing to GHGs are considered

Boundary 3-the 50-year period highlighted in the stabilisation wedges strategy (Bahor et al., 2009) is assumed to start in 2008

Boundary 4-the GHG emissions generated by the waste exported from Malta will not be included in Malta's GHG emissions inventory

Boundary 5-variations with time of the MSW composition will not be accounted for in this study

Boundary 6-predictions on population variation were based on an extrapolation of trends from currently available data

Boundary 7-the Maltese MSW per capita prediction was performed by evaluating the trend of currently available data

Boundary 8- to follow the strategy of the stabilisation wedges this study only deals with MSW and waste that has similar composition to MSW (Bahor et al., 2009)

Boundary 9-the new incineration plant is assumed to be equipped with state-of-the-art technology (JRC, 2007).

Boundary 10-rejects from mechanical biological treatment (MBT), incineration and recycling plants that do not have further use are landfilled (JRC, 2007)

Boundary 11 - two planned MBT plants and one incinerator are assumed to start operations in 2008. The same starting date is also adopted for local recycling.

\section{Scenarios}

Various scenarios were selected for this particular LCA study, as detailed in Table 1. These include the business-as-usual (BAU) and nine other scenarios that utilise several waste treatments according to the percentages shown in Table 1 . The waste treatments considered include landfilling, MBT, incineration, local recycling and waste export. Scenarios 2-9 are in line with the EU's landfill directive targets (EU, 1999). Furthermore, effort was made so that these scenarios reflect realistic Maltese characteristics.

When considering the waste treatment activities in Table 1 the following clarifications should be noted: 
Table 1. Waste management scenarios in percentages.

\begin{tabular}{|c|c|c|c|c|c|c|}
\hline & $\begin{array}{l}\% \\
\text { Landfilling }\end{array}$ & $\%$ MBT & $\begin{array}{l}\% \\
\text { incineration }\end{array}$ & $\begin{array}{l}\% \text { Local } \\
\text { recycling }\end{array}$ & $\begin{array}{l}\% \text { Waste } \\
\text { export }\end{array}$ & $\begin{array}{l}\text { Waste } \\
\text { trend }\end{array}$ \\
\hline Scenario BAU & 93 & 0 & 0 & 0 & 7 & WI \\
\hline Scenario 1 & 75 & 12 & 0 & 0 & 13 & WI \\
\hline Scenario 2 & 50 & 30 & 0 & 0 & 20 & WI \\
\hline Scenario 3 & 25 & 30 & 25 & 0 & 20 & WI \\
\hline Scenario 4 & 25 & 30 & 25 & 10 & 10 & WI \\
\hline Scenario 5 & 10 & 40 & 25 & 25 & 0 & WI \\
\hline Scenario 6 & 0 & 40 & 25 & 35 & 0 & WI \\
\hline Scenario 7 & 25 & 30 & 25 & 10 & 10 & WR \\
\hline Scenario 8 & 10 & 40 & 25 & 25 & 0 & WR \\
\hline Scenario 9 & 0 & 40 & 25 & 35 & 0 & WR \\
\hline
\end{tabular}

BAU: business-as-usual; MBT: mechanical biological treatment; WI: waste increase; WR: waste reduction.

- landfilling is considered to consist of the only landfill that is currently in operation on the islands. This is a sanitary landfill with gas collection (Putzulu-Caruana, 2010)

- MBT refers to the current MBT and AD plant in operation (at Sant' Antnin) and another two plants that, according to the Maltese waste management strategy (MRRA, 2009a), are planned to be built in the coming years

- incineration refers to an incineration plant that, according to the Maltese waste management strategy (MRRA, 2009a), is planned to be built in the near future

- local recycling refers to the recycling of recyclable constituents of MSW processed in Malta

- waste export refers to the export of waste (mainly consisting of recyclables) for treatment outside Malta

- in these scenarios, two different waste trends are followed, denoted in the last column of Table 1 as waste increase (WI) and waste reduction (WR). The WI trend considers the current MSW generation rate, which is increasing at a rate of $2.4 \%$ per annum (MRRA, 2009a). The other trend (WR) assumes that the MSW generation has a reducing trend. For the Maltese islands, a MSW per capita reduction of $30 \%$ in 50 years is assumed in order to override the increasing trend and introduce changes into the Maltese waste management system at slower rates. This percentage reduction and time frame were obtained by considering various literatures and their applicability to the Maltese islands.

Scenario BAU-the BAU scenario considers the situation present in the year 2008 and assumes that the trend remains the same for the future

Scenario 1-this scenario is focused on the Sant Antnin MBT waste treatment plant that is currently in operation. When this plant reaches full capacity, it should be able to treat around onethird of the Maltese MSW

Scenario 2-this scenario is focused on the situation in which the three MBT plants mentioned by MRRA (2009a) are in place. These plants are assumed to be commissioned in 2008 to allow for a fair comparison amongst the various scenarios.
Scenario 3-this scenario is similar to scenario 2; however, $25 \%$ of the waste previously directed to landfilling is now shifted to an incineration plant that is planned to be built, according to MRRA (2009a). These plants are assumed to be commissioned in 2008 to allow for a fair comparison amongst the various scenarios

Scenario 4-the fourth scenario is very similar to scenario 3. However, in this scenario there is the introduction of local recycling.

Scenario 5-in this scenario, MBT is assumed to take $40 \%$ of the total MSW generated in the Maltese islands. Furthermore, this scenario places further emphasis on local recycling (mainly dry recyclables)

Scenario 6-this is a very particular scenario because it assumes no landfilling, whereas in reality, in the Maltese islands, there is a large tendency towards landfilling (ADI-Associates, 2009). This scenario assumes that no waste is directed to landfilling except for the waste that may be output from other MSW treatment processes

Scenario 7-scenario 7 is similar to scenario 4, but with consideration of the waste reduction trend

Scenario 8-scenario 8 is similar to scenario 5, but with consideration of the waste reduction trend

Scenario 9-scenario 9 is similar to scenario 6, but with consideration of the waste reduction trend.

This research made use of three different software packages: the IPPC-Model (IPCC, 2006), the SWM-GHG calculator (KfW, 2011) and Vensim (Ventana-Systems, 2011). The first two packages are used for the numerical calculations of GHG emissions, while Vensim is used to pictorially model some of the waste management scenarios and their effects as a causal-loop diagram (CLD). An example of a CLD is shown in Figure 1. The CLD provides an insight on how several variables within the waste management sector are interlinked together as a conceptual cause-and-effect model. The variables considered range from sources of waste, to treatment activities, to GHG emissions. Positive links depict similar trends between the cause and effect variables written at the two ends of a link, whereas negative links 


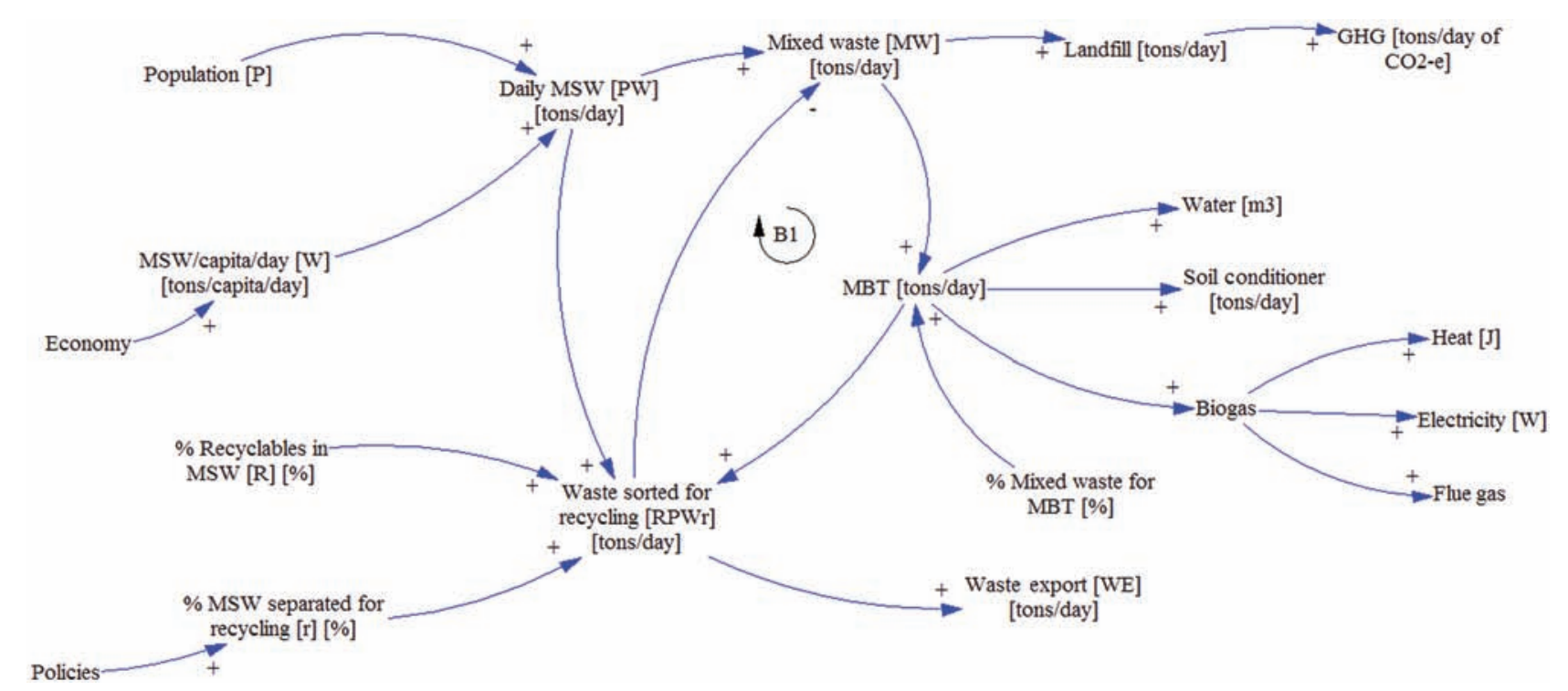

Figure 1. Causal loop diagram (CLD) for scenario 2. GHG: greenhouse gas; MBT: mechanical biological treatment; MSW: municipal solid waste.

depict an opposing trend. Figure 1 is actually representing the CLD for scenario 2. It shows that economic growth in the country tends to increase the MSW/capita/day, which increases the daily MSW. The latter is also increased by an increase in population. An increase in daily MSW leads to an increase in mixed waste, waste directed to MBT and the waste sorted for recycling. The latter is increased by policies encouraging people to separate their waste for recycling and by the percentage of recyclables present in MSW, which is denoted as an exogenous variable. An increase in the waste sorted for recycling variable results in an increase in waste export and a reduction in waste allocated for landfilling, which is a major source of GHG emissions. An increase in the waste directed for MBT leads to an increase in second class water (from waste), soil conditioner and biogas. Biogas, in turn, leads to heat, electricity and flue gas.

The SWM-GHG software tool was employed 11 times for each scenario to calculate the GHG emitted every 5 years (until 50 years), each time setting the corresponding amount of MSW generated. The MSW generated in 50 years time was obtained by further calculations based on the present statistics. While the IPCC-model is employed once for every scenario (as it outputs the GHG emitted over a number of years), in this case a 50-year timeframe was set. The IPCC model outputs the results in terms of quantities of $\mathrm{CH}_{4}$ because it is the predominant gas emitted by landfilling. These results are then converted to $\mathrm{CO}_{2}$-e in order to conform with the integrated waste management stabilisation wedge (Bahor et al., 2009; Pacala and Socolow, 2004). In order for the software to output realistic results, Malta-specific information, such as waste composition, efficiency of gas collection and type of treatment of landfill gas, was used as input.

The IPPC-Model only deals with landfills and these results are slightly more accurate than those output by the SWM-GHG Calculator. Thus, in order to benefit from the advantages of both software packages, the principles of data fusion are used to couple the GHG generated from landfilling as calculated by the IPPC-Model, with the GHG generated from MBT, incineration, and local recycling as calculated by the SWM-GHG Calculator. Ultimately, the final result obtained is a GHG trend for each designed scenario, as presented in Figures 2 and 3.

\section{Results}

The 50-year annual GHG trends, commencing in 2008, for each of the 10 scenarios described previously are plotted in Figure 2. These plots were obtained by calculating (through LCA software) the GHG emitted from each waste treatment adopted within the waste management scenario. The trend for scenario 2 is practically horizontal, indicating that the annual GHG emissions remain more or less constantly stabilized at 2008 levels. This is called the stabilisation scenario by Bahor et al. (2009). It is used together with the BAU scenario to form the integrated waste management stabilisation wedge for the Maltese islands depicted in Figure 3.

The area between the two plots in Figure 3 represents Malta's integrated waste management stabilisation wedge. This denotes the amount of GHG that could be prevented from being emitted into the atmosphere through the adoption of scenario 2 (Pacala and Socolow, 2004). The area was calculated using mathematical integration with respect to time (in years) of the two polynomials fitted to the GHG trends. The adoption of scenario 2, for 50 years post-2008, 16.6 Mt less $\mathrm{CO}_{2}$-e gases would be emitted when compared with a BAU situation.

\section{Discussion}

The different GHG trends shown in Figure 2 indicate high diversification in the designed waste scenarios presented in Table 1. This is exhibited by the fact that the 10 scenarios start from the 


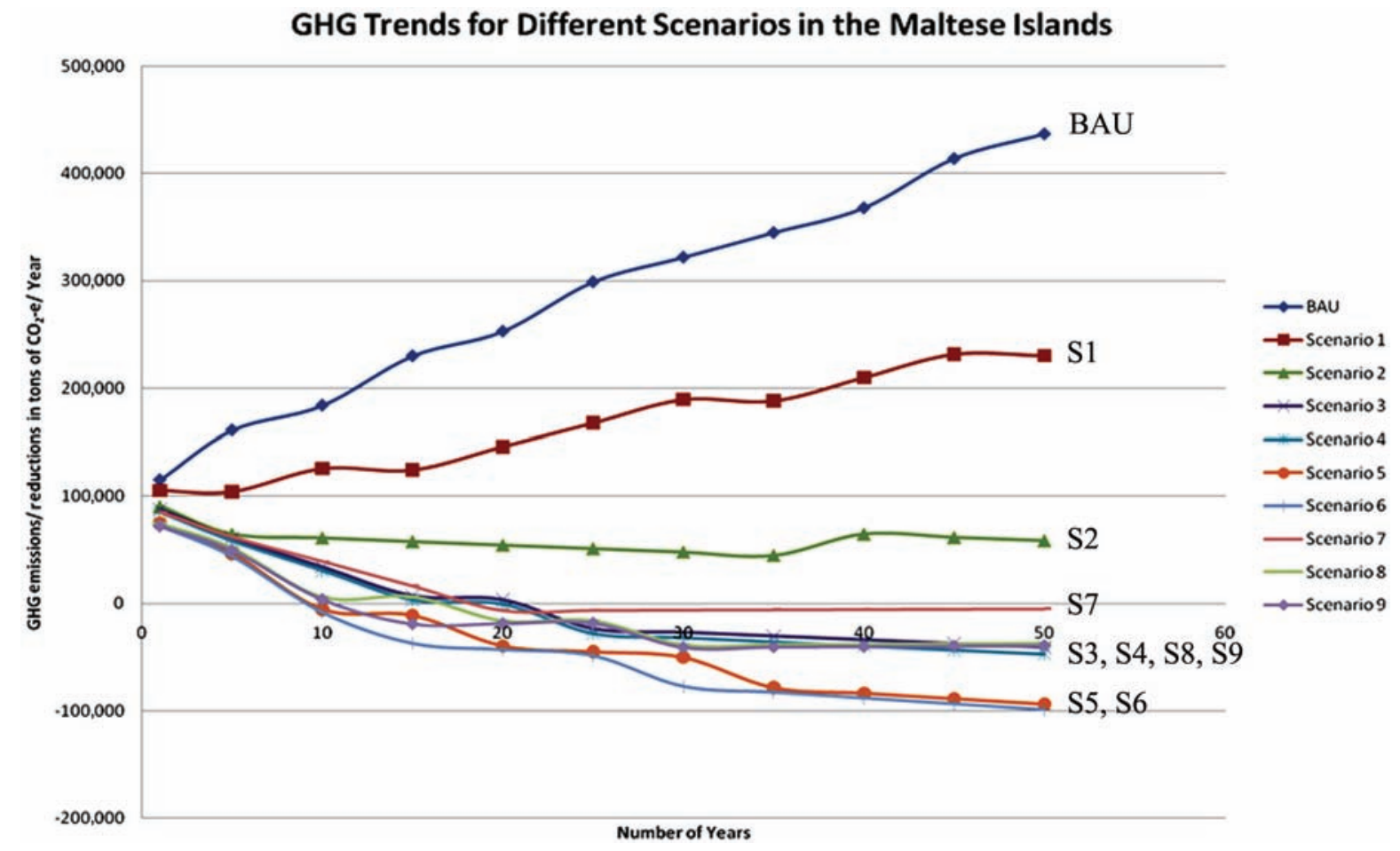

Figure 2. The Maltese islands' greenhouse gas (GHG) trends output by waste management.

\section{The Maltese Islands' Integrated Waste Management Stabilization Wedge}

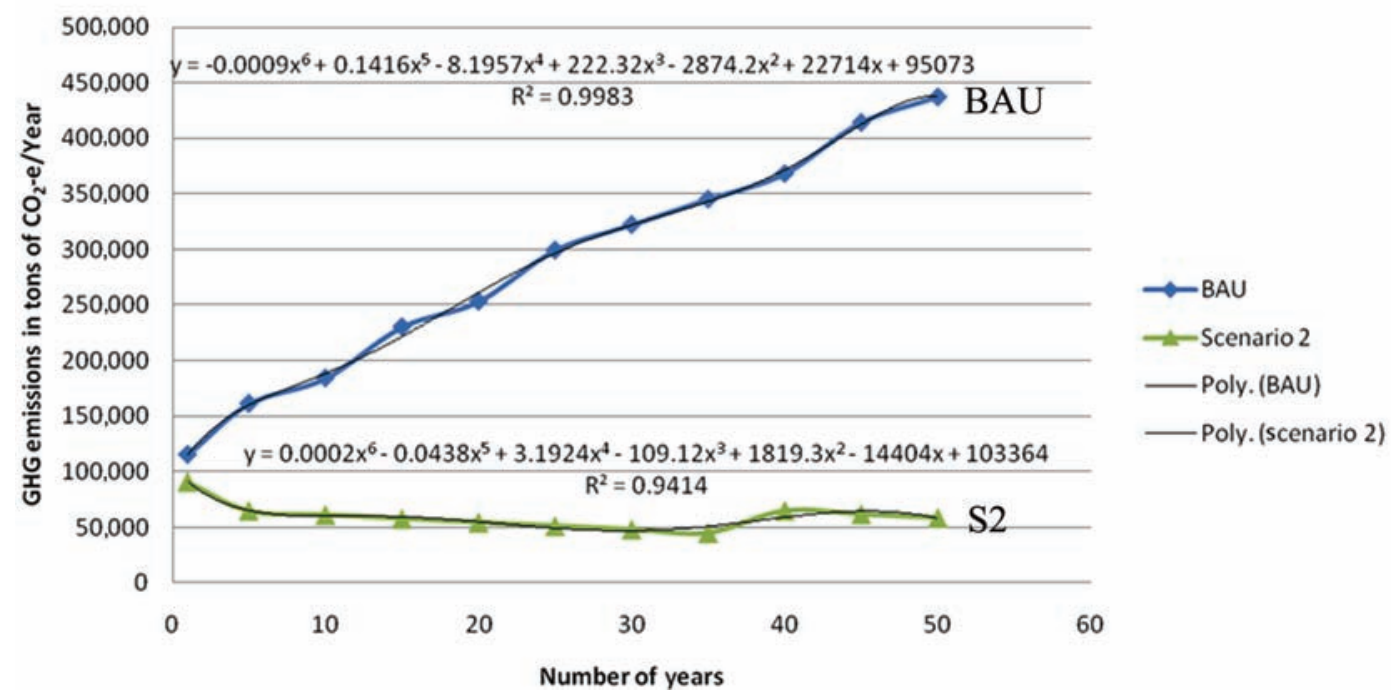

Figure 3. The Maltese islands' stabilization wedge. BAU: business-as-usual; GHG: greenhouse gas.

same point in year 1 (100 kt/year of $\mathrm{CO}_{2}$-e), but end up at 6 distinctive levels in year 50 . These results are summarized in Table 2.

The BAU scenario trend increases at a nearly constant rate up to a level of $437 \mathrm{kt} / \mathrm{year}$. The trend of scenario 1 starts with a very minimal decrease in GHG emissions and then increases to the point when it reaches $230 \mathrm{kt} /$ year of $\mathrm{CO}_{2}$-e after 50 years.

Lower GHG emissions are yielded by scenario 2, which starts with a small decrease in the GHG emissions until the point at which it reaches $51 \mathrm{kt}$ of $\mathrm{CO}_{2}$-e in the year 2042. Following this, the emissions increase again to $59 \mathrm{kt}$ of $\mathrm{CO}_{2}$-e in 2057.

The GHGs emitted in scenario 2 never exceed the emissions of the starting year. Thus, scenario 2 is in conformance with the stabilisation wedge scenario. This shows that the waste management options which make up the stabilisation wedge scenario for the Maltese islands (scenario 2) differs from the global integrated waste management scenario proposed by Bahor et al. (2009). This difference in scenarios, summarised in Table 3 , clearly 
Table 2. Emissions at year 50 for the different scenarios in $\mathrm{kt}$ of $\mathrm{CO}_{2}$-e/year.

\begin{tabular}{llllllll}
\hline Scenario & BAU & 1 & 2 & 3,4 & 5,6 & 7 & 8,9 \\
\hline $\begin{array}{l}\text { Fiftieth year emissions in kt } \\
\text { of } \mathrm{CO}_{2} \text {-e/year }\end{array}$ & 230 & 59 & -40 & -95 & -5 & -40 \\
\hline
\end{tabular}

BAU: business-as-usual.

Table 3. Scenario 2 in comparison with the global waste wedge scenario.

\begin{tabular}{llcl}
\hline & Landfill & Incineration & $\begin{array}{l}\text { Recycling (including } \\
\text { MBT and export) }\end{array}$ \\
\hline Scenario 2 & $50 \%$ & 0 & $50 \%$ \\
Global scenario & $18 \%$ & $36 \%$ & $46 \%$ \\
\hline
\end{tabular}

MBT: mechanical biological treatment.

demonstrates that each country has its own unique characteristics, which highly influence the selection of the optimal waste management regime.

Scenarios 3-9 all yield a GHG reduction within the 50-year period. This is in conformance with the works of Christensen et al. (2009), who note that waste management is one of the unique GHG emission sectors that can lead to emission reductions.

The GHG trends of scenarios 3 and 4 exhibit a GHG reduction of $40 \mathrm{kt} /$ year of $\mathrm{CO}_{2}$-e corresponding to a $9.2 \%$ reduction (when compared to the BAU scenario). The GHG decrease in this case can be attributed mainly to the combination of a decrease in landfilling and an increase in MBT and incineration.

Scenarios 5 and 6 both exhibit similar trends which lead to the highest GHG reductions of around 95 kt/year of $\mathrm{CO}_{2}$-e in 2057, corresponding to a $22 \%$ reduction (when compared to the BAU scenario). This high emission reduction is attributed mainly to minimal landfill use and recycling of large amounts of MSW.

The GHG trend of scenario 7 decreases until the year 2027. This is followed by a constant GHG reduction until the point when it reaches $5 \mathrm{kt} /$ year of $\mathrm{CO}_{2}$-e. The GHG trend of scenario 7 indicates that MSW activities leave no carbon footprint on the environment. Furthermore, scenarios 8 and 9 exhibit a similar GHG trend as that followed by scenarios 3 and 4 .

When comparing the scenarios that assume a waste increase trend (BAU, 1-6) with those that assume a waste reduction trend (7-9), one can see a clear relationship: the higher the amount of waste recycled, the higher the amount of GHG recovered (i.e. GHG recovered is proportional to waste recycled). This relationship was obtained from the consideration of mixed MSW including recyclables.

It was shown previously that the area of the Maltese integrated waste management stabilisation wedge amounts to around 16.6 $\mathrm{Mt} \mathrm{CO}_{2}$-e, which represents the cumulative savings of GHG emissions in $\mathrm{CO}_{2}$-e over a 50-year time span obtained when implementing scenario 2. Although this figure is very small relative to the $200 \mathrm{Gt}$ worldwide target sought by the stabilisation wedges initiative (Pacala and Socolow, 2004), such a reduction is

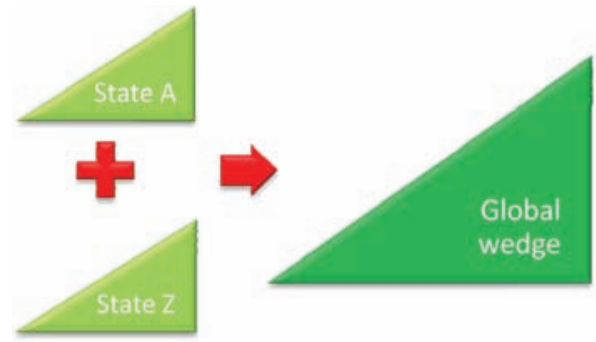

Figure 4. The contribution of individual states towards a global wedge in the stabilisation wedges strategy.

enough for the Maltese islands to conform to this strategy because, ultimately, the global target can only be reached by the collective international contribution from different countries. This concept is shown pictorially in Figure 4, where the integrated waste management wedges of various states are summed to form a global wedge. The size and composition of the wedges of individual states need not be equal but are dependent on the conditions of the state itself.

\section{Policy implementation}

Apart from policies leading to the implementation of the stabilisation wedge resulting from scenario 2, the policy implementation process should also consider the inclusion of other relevant strategies which may be beneficial for an efficient implementation of GHG reduction initiatives. These include the Precautionary Principle, Extended Producer Responsibility, Best Practicable Environmental Option, and the Principles of Proximity and Selfsufficiency (EU, 2010), together with other considerations that reflect Malta's unique necessities.

Policies in Malta should consider a revision of not only the disposal and treatment systems, but also the current MSW collection systems so as to separate the organic fraction from dry recyclables. Furthermore, fiscal incentives can also help to boost public compliance within the implemented schemes.

Ultimately, in any waste management policy implemented in Malta, one must give due consideration to micro-enterprises, which make up more than $95 \%$ of Maltese commerce. When compared with larger businesses, owing to economies of scale, microenterprises face tougher financial difficulties to comply with more demanding waste management schemes (Schembri M and Falzon C, February 2010, personal communication).

\section{Conclusion}

This study shows that the use of an integrated waste management stabilisation wedge has the potential of enriching the policy toolbox of decision-makers for the reduction of GHGs emitted in the Maltese islands. Two distinguishable results arising from this work are the GHG trends of Figure 2 and the Maltese stabilization wedge of Figure 3. The analysis shows that the scenario which is most consistent with the stabilisation wedge strategy for the Maltese islands consists of 50\% landfilling, 30\% mechanical biological treatment and $20 \%$ recyclable waste export for 
recycling. It is calculated that $16.6 \mathrm{Mt}$ less $\mathrm{CO}_{2}$-e gases would be emitted over 50 years by means of this integrated waste management stabilisation wedge when compared to the BAU scenario. The analysis also shows that each country needs to find its own unique solution to reduce effectively its GHG emissions from MSW and that there exists no generic universal solution that is equally applicable to all countries.

\section{Funding}

This research received no specific grant from any funding agency in the public, commercial or not-for-profit sectors.

\section{Acknowledgements}

The authors acknowledge the contribution of the reviewers for their insightful comments which have greatly improved the presentation of this article.

\section{Reference}

ADI-Associates (2009) Strategic Enviornmantal Assessment on the Solid Waste Strategy for the Maltese Islands: Consultation Document January 2009. San Gwann, Malta: Adi Associates Environmental Consultants Ltd.

Bahor B, Van-Brunt M, Stovall J and Blue K (2009) Integrated waste management as a climate change stabilisation wedge. Waste Management \& Research 27: 839-849.

Christensen TH, Gentil E, Boldrin A and Larsen AW (2009) C Balance, carbon dioxide emissions and global warming potentials in LCA-modelling of waste management systems. Waste Management \& Research 27: $707-715$.

EU (European Union) (1999). Council Directive 1999/31/EC of 26 April 1999 on the Landfill of Waste. Brussels: EU.

EU (European Union) (2005) Communication from the Commission to the Council, the European Parliament, the European Economic and Social committee and the Committee of the Regions - Winning the Battle Against Global Climate Change $\{$ SEC(2005) 180\}. Official Journal of the EU Brussels: EU, 35: 6-7.

EU (European Union) (2010). Being Wise with Waste: The EU's Approach to Waste Management. Brussels: Publications Office of the European Union.

Eurostat (2010) Europe in Figures - Eurostat Yearbook 2010. Brussels: Publications Office of the European Union.

Eurostat (2011) Total population. Available at: http://epp.eurostat.ec.europa. $\mathrm{eu} / \operatorname{tgm} /$ table.do?tab=table \&plugin=1\&language=en \&pcode=tps00001 (accessed 29 June 2011).
Ginige T (2008) Waste today gone tomorrow - sustainable waste management: Malta, a case study. In: RICS construction and building research conference, Dublin, Ireland, 4-5 September 2008. Dublin: RICS.

Hotinski R (2007) Stabilization Wedges: A Concept \& Game. Carbon Mitigation Initiative. Princeton, USA: Princeton Environmental Institute, at Princeton University, pp. 1-3.

IPCC (Intergovernmental Panel on Climate Change) (2006) IPCC guidelines for national greenhouse gas inventories. Available at: www.ipcc-nggip. iges.or.jp/public/2006gl/.../IPCC_Waste_Model.xls (accessed 15 June 2011).

JRC (Joint Research Centre) (2007) Environmental Assessment of Municipal Waste Management Scenarios: Part I - Data Collection and Preliminary Assessments for Life Cycle Thinking Pilot Studies. Luxembourg: European Commission, JRC and Institute for Environment and Sustainability.

KfW (2011) Greenhouse gas calculator. Available at: http://www.kfwentwicklungsbank.de/EN_Home/Sectors/Waste_management/Solid_ Waste_Management_Greenhouse_Gas_Calculator/index.jsp (accessed 23 June 2011).

Micallef A and Sammut CV (2010) The Second Communication of Malta to the United Nations Framework Convention on Climate Change. Floriana, Malta: Ministry for Resources and Rural Affairs.

MRA (Maltese Resource Authority) (2011) Annual Report for Submission under the United Nations Framework Convention on Climate Change. Marsa: Malta: Malta Resouce Authority.

MRRA (Ministry for Resources and Rural Affairs) (2009a). A Solid Waste Management Strategy for the Maltese Islands. Floriana, Malta: MRRA.

MRRA (Ministry for Resources and Rural Affairs) (2009b). Waste Management Plan for the Maltese Islands 2008-2012. Floriana, Malta: MRRA.

NSO (National Statistics Office) (2010a) Demographic Review 2009. Valletta: Malta Statistics Office.

NSO (National Statistics Office) (2010b) Malta in Figures 2010. Valletta: Malta Statistics Office.

Pacala S and Socolow R (2004) Stabilisation wedges: Solving the climate problem for the next 50 years with current technologies. Science 305: 968-972.

Putzulu-Caruana H (2010) Practical aspects of waste management. ISAT \& SERM Lecture Presentation, Malta. November 2010, University of Malta - Valletta Campus

Skovgaard M, Hedal N and Villanueva A (2008) Municipal waste management and greenhouse gases. In: Isoard S (ed). Copenhagen: European Environment Agency, pp. 38.

Ventana-Systems (2011) Vensim. Available at: http://www.vensim.com/ (accessed 25 January 2011).

WasteServ (2008) Sustainable Waste Management for the Maltese Islands in 5 Years of Achievement. Marsaskala: Malta: MPS Limited.

WasteServ (2011) Waste Management in the Maltese Islands - Current and Future Challenges. Marsaskala, Malta: WasteServ Malta Ltd. 